\title{
Perceived Social Disconnectedness, Low Frustration Tolerance and Coping with Uncertainty in Mothers of Children Diagnosed With Cerebral Palsy
}

\author{
Hafiza Tuba Qamar ${ }^{1}$, Ms. Sara Latif ${ }^{2}$ \\ ${ }^{1}$ Riphah Institute of Clinical and Professional Psychology, Riphah International University, Lahore, Pakistan. \\ ${ }^{2}$ Lecturer, Riphah Institute of Clinical and Professional Psychology, Riphah International University, Lahore, \\ Pakistan. \\ *Corresponding author information: Tuba Qamar, tubaqamar3@gmail.com
}

Received 20 June 2020;

Accepted 30 June 2020;

Published 09 July 2020;

\begin{abstract}
The present study was conducted to investigate the relationship among perceived social disconnectedness, low frustration tolerance and coping with uncertainty in mothers of children diagnosed with cerebral palsy. The current study used correlational research design. Hundred participants were collected through non-probability purposive sampling technique. Data was drawn from both government and private special education centers of Lahore within six months. Perceived social disconnectedness scale, low frustration tolerance checklist and coping with uncertainty scale were used to measure variables under study. Correlational analysis showed highly significant negative association of social disconnectedness and low frustration tolerance with coping with uncertainty. Findings also showed significant predicting role of social disconnectedness and low frustration tolerance on coping with uncertainty in mothers of children diagnosed with cerebral palsy.
\end{abstract}

Keywords: Perceived Social Disconnectedness, Low Frustration Tolerance and Coping with Uncertainty, CP Child's Mothers

\section{INTRODUCTION}

The aim of the present study was to investigate the association among Perceived Social Disconnectedness, Low Frustration Tolerance and Coping with Uncertainty in Mothers of Children diagnosed with Cerebral Palsy. Researcher also aimed to identify the predicting role of perceived social disconnectedness and low frustration tolerance on coping with uncertainty.

\section{Perceived Social Disconnectedness}

Social disconnectedness is a type of social isolation that is characterized by determine in participation in social activities as well as lack of social relationships (Cornwell \& Waite, 2009). It can be further described as a limited or lack of social contact that an individual has with others to include situational factors that may cause them to feel uncomfortable or out of place. Social disconnectedness has been found to display atrophy, loss, or deterioration of internal bonding and can further be identified by aimlessness and apathy with regards to major life experiences, as well as the deterioration of external bonds (Brennan \& Auslander, 1979). Social disconnectedness can be described by infrequent contact with others as noted by situational aspects, such as the lack of involvement in groups, social events, or limited social interactions.

Previous studies have indicated that mothers who have children with disability tend to experience feelings of either social disconnectedness or perceived isolation, which affects their health in a more negative manner (Cornwell \& Waite, 2009).

\section{Low Frustration Tolerance}

Tolerance is defined as the ability to overcome challenges and endure stressful events. An individual feel frustrated when he experiences stressful situations. Low tolerance to frustration occurs when a goal-oriented intervention is postponed or remain unfulfilled. The underlying feeling are unhappiness and frustration about unmet needs or unresolved problems (Esposito, 2018). Many people with low frustration tolerance are unable to bear things which are out of their mood and desire, they get frustrated easily and show aggression. Many express it verbally and some turn to physical violence when provoked (Russo, 2017).

Moreover, Low frustration tolerance can be experienced by individuals due to many reasons such as, limitation negative life event, caregiving burden and other hindrances in life and ties. So, frustration tolerance depends on upon the circumstances, where a 
mother of disable children is disappointed or endures the baffled circumstances (Rodriguez, 2013).

\section{Coping with Uncertainty}

Coping with uncertainty, as suggested by Folkman (2010), refers to "the thoughts and behaviors individuals utilize to handle the internal and external difficulties of stressed out events". Mishel (2009) described uncertainty as "an unexpected stressful event". However, pressure below these unexpected situations differs depending on the efforts of a person to assess and cope with the situation (Averill, Olbrich \& Lazarus, 1972).

However, having child with disability is a major event that negatively affects families, and force families to re-evaluate its plans, goals, and relationships in light of restrictions and limitations associated with child's disability, and resultant stresses in parents, and their efficiency in coping with these stresses. During re-evaluation process, families tend to utilize available support resources, or look for alternative ones, as an attempt to adopt strategies to regain equilibrium between family's resources and disability demands to cope with stresses associated with the child's disability (Woodman, \& Hauser, 2013). Knowing nature and levels of stresses faced by families of children with disabilities and efficiency of coping strategies they use, are crucial issues in family counseling programs, and should be main pillar in training programs for those parents, as they are more likely to face the developmental deficiencies and challenges in child with disability, (Glidden, 2012).

\section{LITERATURE REVIEW}

A research was conducted to examine the impact of disability on social disconnection and perceived isolation of the caregiver. Context and psychosocial theories provided the best context for this research on how parent's loneliness and disconnection can be influenced by child's disability. Findings showed that mothers having children with disabilities between the ages of 18 and 49 reported more social disconnection than women of the same age group with normal children (Jopling, 2015).

Another study was conducted to examine a variety of indicators of isolation and capture the information using two scales to determine perceived isolation and social disconnectedness and the effects they have on the mental and physical health of mothers having children with disability. The findings have determined that perceived isolation and social disconnectedness are not interchangeable indicators. Rather, they have distinct and separate associations with mental and physical health of mothers (Cornwell $\&$ Waite, 2009).

In addition, another study investigated whether perceived stress and distress, emotion dysregulation, and frustration intolerance independently predicted risk of parent child aggression in a sample of 81 couples. Findings indicated that each of the risk factors uniquely predicted parent child aggression risk. Moreover, results revealed a significant difference in the pattern of these relationships between mothers and fathers (Baker, Doris, \& Tucker, 2017).

Table 1

\section{Hypotheses}

- There is likely to be a relationship between Perceived Social Disconnectedness and Coping with Uncertainty.

- There is likely to be a relationship between Low Frustration Tolerance and Coping with Uncertainty.

- There is likely to be a predictive role of Perceived Social Disconnectedness and Low Frustration Tolerance on Coping with Uncertainty.

\section{METHOD}

\section{Research Deign}

Correlational research design was used to investigate the relationship among perceived social disconnectedness, low frustration tolerance and coping with uncertainty in mothers of children diagnosed with Cerebral Palsy.

Sample

The sample size was 80 mothers of Children diagnosed with Cerebral Palsy. The sample size was determined by "G- Power Analysis".

\section{Sampling Technique}

Non-probability Purposive Sampling strategy was employed

\section{Measures}

Assessment measures included the following.

\section{Demographic Information}

Information regarding participants name, age, gender, qualification, monthly salary, residence, socio economic status, number of siblings, and family system etc. was collected via selfdevised demographic questionnaire.

\section{Perceived Social Disconnectedness Scale}

Perceived Social Disconnectedness Scale was originally developed by Lee and Robbins (1995). The items were rated on five-point likert scale. The scale consisted of 8 items. This scale has an internal consistency.92, and has well established construct validity. Cronbach's alpha reliability of this scale in the current study comes out to be .74 .

\section{Low Frustration Tolerance Checklist}

Low frustration tolerance checklist was originally developed by (Rehman et al., 2008). This checklist has 56 items. This checklist used 5-point likert scale ( $1=$ strongly agree, $5=$ strongly disagree). Cronbach's alpha reliability of this checklist was .94.

\section{Coping with Uncertainty Scale}

Coping with uncertainty scale was originally developed by Veronica and Derek, (2001). This scale has 40 items. This tool was based on 5point likert scale ( $1=$ always, $5=$ never $)$. The chronbach alpha reliability of this scale was .80 .

\section{Procedure}

The participants were approached at different public and private special education centers. Each participant was provided with the Information Sheet for detail information regarding the research and a Consent Form to make sure that the participants were willingly participating in the research. They were informed about the ethical consideration of the study. After that pilot study and main study was conducted.

\section{Results}

Data was analyzed using Statistical Packages for Social Science (SPSS.21).

Pearson Product Moment Correlation Analysis between Study Variables among Mothers of CP Children (N=80)

\begin{tabular}{|l|l|l|l|l|l|l|}
\hline & Variables & $\mathbf{1}$ & $\mathbf{2}$ & $\mathbf{3}$ & $\mathbf{M}$ & SD \\
\hline 1. & Perceived Social Disconnectedness & - & .16 & $-.33^{* *}$ & 70.41 & 14.86 \\
\hline 2. & Low Frustration Tolerance & - & - & $-.30^{* *}$ & 54.03 & 19.56 \\
\hline
\end{tabular}


3. $\quad$ Coping with Uncertainty $* * \mathrm{P}<0.01, * \mathrm{P}<0.05$

The results in above table showed Perceived Social Disconnectedness and Low Frustration Tolerance have highly significant negative association with Coping with Uncertainty.

\section{Table 2}

Hierarchal Regression Analysis Predicting Coping with Uncertainty $(n=80)$

\begin{tabular}{|l|l|l|}
\hline & & Coping with Uncertainty \\
\hline & & Mothers of CP Child \\
\hline Predictors & $\mathbf{R}^{2}$ & $\boldsymbol{\beta}$ \\
\hline Step 1 & & \\
\hline Mother Age & $.4^{0 * * *}$ & $.26^{* *}$ \\
\hline Mother Education & & $.30^{* *}$ \\
\hline Residence & & $-.35^{* *}$ \\
\hline Step 2 & & \\
\hline Perceived Social Disconnectedness & $.41^{*}$ & $-.07^{*}$ \\
\hline Step 3 & & \\
\hline Low Frustration Tolerance & .44 & -.25 \\
\hline Total R & & \\
\hline
\end{tabular}

Note: $* \mathrm{p}<.05 .,{ }^{* *} \mathrm{p}<.01 ., * * * \mathrm{p}<.001$.

a. Dependent Variable: Coping with Uncertainty

b. Predictors in the Models: Mother Age, Mother Education, Residence, Perceived Social Disconnectedness, Low Frustration Tolerance.

Results in above table revealed that demographic variables and perceived social disconnectedness were significant predictors of coping with uncertainty.

\section{DISCUSSION}

Results of the current study showed that social disconnectedness has a significant negative association with coping with uncertainty among mothers having children diagnosed with cerebral palsy children. Baqutayan (2015) conducted a study to understand the relationship of stress-related issues and coping mechanisms. The findings showed that the relationship between social disconnectedness and coping was negative. Moreover, results of current research have shown that Low Frustration Tolerance has a significant negative association with Coping with Uncertainty among mothers with cerebral palsy. Another research was conducted to study the association between coping and in tolerance of uncertainty in students. Results revealed Low Frustration Tolerance have significant negative association with Coping with Uncertainty. In specific, greater optimistic inclinations were directed to lesser levels of intolerance of uncertainty (Dugas, Freeston \& Ladouceur,2014). Furthermore, findings of the current investigation revealed that Social Disconnectedness was a significant predictor of Coping with Uncertainty among mothers having children diagnosed with cerebral palsy. A study was conducted to assess the effect between social disconnectedness and coping with uncertainty among parents of special children. Results showed that social disconnectedness significantly predicted the coping with uncertainty (Heuvel et al., 2014).

\section{CONCLUSION}

Hence, it is concluded that perceived isolation and social disconnectedness are more likely to be seen amongst mothers having children with disability (Cornwell \& Waite, 2009). These two forms of isolation have distinctive and separate relations with an individual's health both physically and mentally. It is evident from the current research and previous researches that mothers having cerebral palsy children who experienced high social disconnectedness, have low frustration tolerance which lead towards poor coping with uncertainty. It is important to understand how these mothers are able to adapt to various changes in their lives, and how environmental, physiological, and psychological factors may affect a mother's companionship and social connectedness. My hope is that this research will offer valuable information for future generations of researchers and health care providers.

\section{REFERENCES}

[1] Baqutayan, Shadiya. (2015). Stress and Coping Mechanisms: A Historical Overview. Mediterranean Journal of Social Sciences. 6. 10.5901/mjss. 2015.v6n2s1p479.

[2] Brennan, T., \& Auslander, N. (1979). Adolescent loneliness: An exploratory study of social and psychological pre-dispositions and theory. Washington, DC: National Institute of Mental Health, Juvenile Problems Division.

[3] Cornwell, E. Y. \& Waite, L. J. (2009). Social disconnectedness, perceived isolation, and health among older adults. Journal of Health and Social Behavior. 50, 31-48. doi:10.1177/002214650905000103.

[4] Christina M. Rodriguez • Levi R. Baker • Doris F. Pu and Meagan C. Tucker (2017). Predicting Parent-Child Aggression Risk in Mothers and Fathers: Role of Emotion Regulation and Frustration Tolerance. J Child Fam Stud. 26:2529-2538 DOI 10.1007/s10826-0170764-y.

[5] Dugas MJ, Freeston MH, Ladouceur R. Intolerance of uncertainty and problem orientation in worry. Cognitive Therapy and Research. $2014 ; 21: 593-606$.

[6] Esposito Vinzi, V., Trinchera, L., \& Amato, S. (2010). PLS path modeling: From foundations to recent developments and open issues for model assessment and improvement. In V. Esposito Vinzi, W. W. Chin, J. Henseler, \& H. Wang (Eds.), Handbook of partial least 
squares. Springer handbooks of computational statistics: Concepts, methods and applications (pp. 47-82). Berlin, Heidelberg: Springer.

[7] Greco, Veronica \& Roger, D.. (2001). Coping with uncertainty: The construction and validation of a new measure. Personality and Individual Differences. 31. 519-534. 10.1016/S0191-8869(00)00156-2.

[8] Glidden LM, Schoolcraft SA. Depression: Its trajectory and correlates in mothers rearing children with intellectual disability. Journal of Intellectual Disability Research: Special Issue on Family Research. 2012;47:250-263.

[9] Heuvel, Claudia \& Alison, Laurence \& Power, Nicola. (2014). Coping with uncertainty: Police strategies for resilient decision-making and action implementation. Cognition, Technology \& Work. 16. 10.1007/s10111012-0241-8.

[10] Joseph V. Russo (2017). Low Frustration Tolerance and How to Deal with It. A Man and His Blog- Commentary and Musings.

[11] Jopling, K. 2015. Promising Approaches to Reducing Loneliness and Isolation in Later Life. Age UK, London. Available online http://www.gulbenkian.org.uk/files/25-06-15-

[12] Lee, R. M., \& Robbins, S. B. (1995). Measuring belongingness: The Social Connectedness and the Social Assurance Scales. Journal of Counseling Psychology, 42, 232-241.

[13] Monat, A., Averill, J. R., \& Lazarus, R. S. (1972). Anticipatory stress and coping reactions under various conditions of uncertainty. Journal of Personality and Social Psychology, 24(2), 237-253. https://doi.org/10.1037/h0033297

[14] Mishel MH, Germino BB, Lin L, Pruthi RS, Wallen EM, Crandell J and Blyler D. (2009). Managing uncertainty about treatment decision making in early stage prostate cancer: a randomized clinical trial. 77(3):349-59. doi: 10.1016/j.pec.2009.09.009.

[15] Monat, A., Averill, J. R., \& Lazarus, R. S. (1972). Anticipatory stress and coping reactions under various conditions of uncertainty. Journal of Personality and Social Psychology, 24(2), 237-253. https://doi.org/10.1037/h0033297

[16] Rodriguez et al (2013) Differences in the Relationship Between Family Environments and Self-Determination among Anglo Latino and Female Students With Disabilities Eric No.ej1034037 Page: 11 ISSN 21651434

[17] Rahman, N. K., Dawood, S., Rehman, N., Mansoor, W., \& Ali, S. (2009). Standardization of Symptom Checklist$\mathrm{R}$ on psychiatric and non-psychiatric sample of Lahore city. Pakistan Journal of Clinical Psychology, 8(2), 21 32.

[18] Woodman AC, Hauser-Cram P. The role of coping strategies in predicting change in parenting efficacy and depressive symptoms among mothers of adolescents with developmental disabilities. J Intellect Disabil Res. 2013;57(6):513-530. doi:10.1111/j.1365- 